\title{
TOWARDS ESTABLISHING AN OPEN CATALOGUE FOR GEOSPATIAL EDUCATIONAL RESOURCES
}

\author{
V. Rautenbach ${ }^{1, *}$, S. Coetzee ${ }^{1}$, A. Çöltekin ${ }^{2}$, C. Pettit ${ }^{3}$, L. Pijper ${ }^{1}$, M. Madden ${ }^{4}$, S. Christophe ${ }^{5}$ and O. Lkhamjav 6 \\ ${ }^{1}$ Centre for Geoinformation Science, Department of Geography, Geoinformatics and Meteorology, University of Pretoria, South \\ Africa - (victoria.rautenbach, serena.coetzee)@up.ac.za, u04461615@tuks.co.za \\ ${ }^{2}$ Institute for Interactive Technologies, University of Applied Sciences and Arts Northwestern Switzerland, Switzerland - \\ arzu.coltekin@fhnw.ch \\ ${ }^{3}$ City Futures Research Centre, Faculty of Built Environment, UNSW - c.pettit@unsw.edu.au \\ ${ }^{4}$ Center for Geospatial Research Department of Geography University of Georgia Athens, Georgia, USA - mmadden@uga.edu \\ ${ }^{5}$ COGIT Lab, IGN-France, Paris, France - sidonie.christophe@ign.fr \\ ${ }^{6}$ Chair of the Mongolian Geospatial Association Ulaanbaatar, Mongolia - ochirkhuyag@geomedeelel.mn
}

Commission IV, WG IV/4

KEY WORDS: educational resource, open education, catalogue, learning object metadata, metadata

\begin{abstract}
:
Existing geospatial educational resources are not always easy to find and to integrate into an academic module, amongst others, because the required metadata is not available. As a consequence, simple search attempts do not bring us to these resources, and we miss out on some material that may be very useful in teaching and learning. Our aim is to develop a searchable catalogue of existing geospatial educational resources that can be used by communities, such as ISPRS or GeoForAll, universities and other educational institutions. The catalogue will index new and existing geospatial educational resources (e.g. electronic textbooks, tutorials, and quizzes) so that the resources can be searched and discovered. Based on the metadata, educators can select appropriate educational resources for integration into an educational event, such as an online course or a module at university level. We believe such an open catalogue of searchable geospatial educational resources is valuable for educators worldwide and will provide students with the opportunity to learn using local and international examples to widen their knowledge. In addition, this future catalogue should broaden overall access to geospatial education and empower communities for the benefit of society. In this paper, we discuss requirements of preparing such a catalogue and some preliminary efforts we have made towards implementing one, including review of 114 existing systems and resources.
\end{abstract}

\section{INTRODUCTION}

Internationally there is a growing need for the development and cataloguing of educational resources (Hylén, 2006; Littlejohn, 2003). At present, a large number of geospatial educational resources, such as tutorials and practical assignments, are available through various platforms, such as Wikis, GitHub, and Moodle.

However, these geospatial educational resources are not always easy to find and to integrate into an academic module, amongst others, because discoverability is poor, and the required metadata is not available. This can be solved by creating a metadata catalogue of geospatial educational resources available. When educational resources are loaded into the metadata catalogue, a complete metadata record for each resource would need to be created. This metadata would allow educators and learners to find appropriate material for their specific pedagogical need.

To address this need of a metadata catalogue of geospatial educational resources, we investigated requirements for implementing an open catalogue that can be used by higher education communities, such as the International Society for Photogrammetry and Remote Sensing (ISPRS) or GeoForAll, universities and other educational institutions. In this paper, we address the following questions: What metadata schema is most appropriate for geospatial educational resources? What are the requirements for such a catalogue? Is there an existing catalogue application that meets all the requirements? This result presented in the paper will be a useful resource for communities that would like to setup a similar catalogue in the future.

The paper is structured as follows: Section 2 provides a brief overview of the Dublin Core and IEEE Standard for Learning Object Metadata (IEEE LOM) schemas and the profile that would be used to describe each geospatial resource in the metadata catalogue. In Section 3, we present and discuss the educational resources catalogued to present. The requirements for the metadata catalogue are presented in Section 4, and in Section 5 five existing applications are evaluated against these requirements. In Section 6, the custom implementation using standard web technologies are presented. Section 7 offers a brief discussion and concluding remarks.

\section{REVIEW OF POSSIBLE METADATA SCHEMAS}

Metadata is often described as 'data about data', or to be more precise, it can be described as information about data. In the context of this paper, metadata provides information about an

* Corresponding author 
educational resource. The reuse of educational resources is only possible when accurate and descriptive metadata is available (Roy et al 2010). The process of creating metadata can be very tedious and time consuming but it is essential for sharing and reuse of educational resources. The metadata allows instructors and students to search or discover the most appropriate and wellsuited educational resources possible.

Our first step was to investigate well-known metadata schemas, such as Dublin Core (ISO, 2009) and the IEEE Standard for Learning Object Metadata, or IEEE LOM (IEEE, 2002). A metadata schema specifies the metadata elements and relationships between them, and in this way provides a blueprint for the metadata to be collected. We (qualitatively) evaluated the well-known metadata schemas to better understand if they are appropriate for geospatial educational resources specifically.

Dublin Core is a general-purpose metadata schema that is widely used to describe digital and physical objects. The Dublin Core Metadata Element Set (DCMES) contains 15 well defined elements for describing the "core" properties of digital and physical objects. However, the DCMES does not contain any elements that can be used for describing the pedagogical information of educational resources (Roy et al 2010).

The IEEE LOM standard was developed specifically for describing learning objects that can be used for learning, education or training. The standard allows users to find learning objects based on the learning resource type, interactivity level and intended end user, for example. Categories of metadata elements include general, life cycle, meta-metadata, technical, educational, rights, relation, annotation and classification. Each of these categories consist of more than one metadata elements. The LOM standard is very comprehensive and can therefore be very tedious to complete. This flexibility is important as the IEEE LOM can be too complex for novice catalogues. Mechanisms for converting between Dublin Core and IEEE LOM does exist, but the aggregation and disaggregation of the metadata fields can affect the usefulness of the resulting metadata.

After the review of Dublin Core and IEEE LOM, we decided to not use either standard as is, but to customize and develop our own profile of IEEE LOM for geospatial educational resources. This was done by annotating various educational resources and reviewing how the elements selected would contribute to the searchability of the educational resources in a catalogue. Table 1 provides an overview of the IEEE LOM elements that was selected for the profile that would be used in the future catalogue implementation.

The profile consists of only 20 metadata elements from the 60 elements that are available within the IEEE LOM standard. After more extensive (planned) user testing at later stages, we might add or remove some elements to ensure that it is easy and fast for contributors to add their material to the catalogue without compromising discovering of resources. Below is an example of how an educational resource can be described using the profile (refer to Table 1).

\section{GEOSPATIAL EDUCATIONAL RESOURCES}

To date, we identified and classified 114 geospatial educational resources. The resources were classified based on the metadata elements identified and described in Table 1 . The list of resources is not yet a complete this of resources and we are still in the process of identifying additional resources.

Firstly, when deciding whether to add a geospatial educational resource into the catalogue, we compared the resource against the IEEE Standard for Learning Object Metadata's definition for educational resources, namely "any digital resource that can be reused to support learning and can be used in multiple contexts" (IEEE, 2002). Educational resources could be of various length and complexities. A resource was considered as a single unit, for example, a book was added to the catalogue as a single resource and not each chapter as a separate resource.

Currently, all the resources identified are English, but we intend to expand the list of resources to cover resources in any language. This would, however, require assistance from (ideally native) speakers from all over the world, possibly a good mechanism for quality checking. Therefore, a multi-lingual version of the planned catalogue would require major initiative and engagement from many parties, thus is a long-term goal.

Of the resources classified, we found that $95 \%$ of the resources are intended for learners and would require a high interactivity level, for example, an exercise or tutorial. From this, it is also clear that the majority of the resources are short exercises intended to teach a specific skill (e.g. performing multi criteria analysis in GRASS GIS) rather than multiple concepts (e.g. textbooks). As a result, we only found eleven textbooks all of which is freely available. Further, $92 \%$ of the resources are intended for higher education (i.e. college or university students) and the remaining $8 \%$ for schools.

A list of keywords based on the title, description and content of the resources were determined. We used these keywords to create a word cloud (Figure 1). From the word cloud, it is clear that the geospatial educational resources focused on data, geographic information system (GIS), QGIS (i.e. a specific GIS software) and geospatial information. Even though ESRI's ArcGIS and ArcMap are present in the word cloud (which are the 'market leaders' in GIS), there is a clear dominance of open source software, such as QGIS, OSM, GRASS, SAGA and GeoServer. This bias might be as we have not yet loaded courses and material available from proprietary software providers. 
Table 1. Overview of the IEEE LOM elements selected for the profile. Adapted from IEEE (2002)

\begin{tabular}{|c|c|c|}
\hline $\begin{array}{l}\text { IEEE LOM profile } \\
\text { element }\end{array}$ & Description & Example \\
\hline \multicolumn{3}{|l|}{ 1. General } \\
\hline 1.1. Identifier & $\begin{array}{l}\text { A unique identifier assigned to a new educational resource } \\
\text { automatically when it is loaded into the catalogue. }\end{array}$ & LyXPYYyblsInhzhHTVSh \\
\hline 1.2. Title & The name given to the educational resource by the authors. & $\begin{array}{l}\text { Multiple Criteria Evaluation in Allocating Land for } \\
\text { Waste Incineration }\end{array}$ \\
\hline 1.3. Language & $\begin{array}{l}\text { The language used within the educational resource to } \\
\text { communicate with the intended end user. }\end{array}$ & English \\
\hline 1.4. Description & A short description of the content of the resource. & $\begin{array}{l}\text { This tutorial instructs a user in basic multi-objective } \\
\text { decision making using a variety of Open Source } \\
\text { software: GRASS GIS, Quantum GIS and OpenOffice } \\
\text { Calc. With it they will be able to import vector and raster } \\
\text { data, convert vectors to raster and use map algebra to } \\
\text { produce a land allocation map according to the factors } \\
\text { and constraints set up by the project }\end{array}$ \\
\hline 1.5. Keywords & The main topics covered in the educational resource. & $\begin{array}{l}\text { GRASS GIS; QGIS; OpenOffice Calc; Multiple Criteria } \\
\text { Evaluation; Suitable site analysis; Land use }\end{array}$ \\
\hline \multicolumn{3}{|l|}{ 2. Life Cycle } \\
\hline 2.1. Version & $\begin{array}{l}\text { The edition of the educational resource. This element would be } \\
\text { very important when a new version or edition of an educational } \\
\text { resource is released. }\end{array}$ & 1 \\
\hline 2.2. Role & $\begin{array}{l}\text { The kind of contributor. For our implementation, we will only } \\
\text { focus on the author and/or publisher. }\end{array}$ & Author \\
\hline 2.3. Entry & $\begin{array}{l}\text { The name or organization that served as the author or publisher } \\
\text { of the educational resource. }\end{array}$ & Ja'far Rogers \\
\hline 2.4. Date & The year the contribution was published in. & 2010 \\
\hline \multicolumn{3}{|l|}{ 3. Educational } \\
\hline $\begin{array}{l}\text { 3.1. Interactivity } \\
\text { type }\end{array}$ & $\begin{array}{l}\text { Predominant mode of learning supported by this learning } \\
\text { project. The options are active (i.e. requires the end user to } \\
\text { complete specified tasks), expositive (i.e. in this case the end } \\
\text { user would be a passive recipient of information) and mixed } \\
\text { (i.e. a combination of both active and expositive learning. }\end{array}$ & Mixed document \\
\hline $\begin{array}{l}\text { 3.2. Learning } \\
\text { resource type }\end{array}$ & $\begin{array}{l}\text { The type of educational resources, for example, is the resource } \\
\text { predominately an exercise, simulation, slides, or an exam. }\end{array}$ & Exercise \\
\hline $\begin{array}{l}\text { 3.3. Interactivity } \\
\text { level }\end{array}$ & $\begin{array}{l}\text { The degree of interactivity required to complete the educational } \\
\text { resource. For example, an exercise would require high } \\
\text { interactivity as the end user would need to complete various } \\
\text { tasks. }\end{array}$ & High \\
\hline $\begin{array}{l}\text { 3.4. Semantic } \\
\text { density }\end{array}$ & $\begin{array}{l}\text { The degree of conciseness of an educational resource. The } \\
\text { semantic density can be estimated when looking at for example, } \\
\text { the size, duration and text density of the resource. }\end{array}$ & Medium \\
\hline $\begin{array}{l}\text { 3.5. Intended end } \\
\text { user role }\end{array}$ & $\begin{array}{l}\text { The principal user for which the educational resource would be } \\
\text { intended for. The two main audiences would be the learner that } \\
\text { uses the resource and the manager that present the material. }\end{array}$ & Learner \\
\hline 3.6. Context & $\begin{array}{l}\text { The environment for which the educational resource was } \\
\text { intended (i.e. school, higher education, training and other). }\end{array}$ & Higher education \\
\hline 3.7. Difficulty & $\begin{array}{l}\text { How hard it is to work with or through this educational resource } \\
\text { for the typical intended target audience. }\end{array}$ & Easy \\
\hline $\begin{array}{l}\text { 3.8. Typical } \\
\text { learning time }\end{array}$ & Approximate time it takes to complete the resource. & 2 hours \\
\hline 3.9. Cost & $\begin{array}{l}\text { Whether the educational resource is freely available or available } \\
\text { at a fee. }\end{array}$ & Free \\
\hline $\begin{array}{l}\text { 3.10. Copyright and } \\
\text { other } \\
\text { restrictions }\end{array}$ & The intellectual property rights of the educational resource. & Public domain \\
\hline \multicolumn{3}{|l|}{ 4. Technical } \\
\hline 4.1. Location & The external universal resource locator (URL) to the resource. & $\begin{array}{l}\text { https://gracilis.carleton.ca/CUOSGwiki/index.php/Multi } \\
\text { ple_Criteria_Evaluation_in_Allocating_Land_for_Wast } \\
\text { e_Incineration }\end{array}$ \\
\hline
\end{tabular}




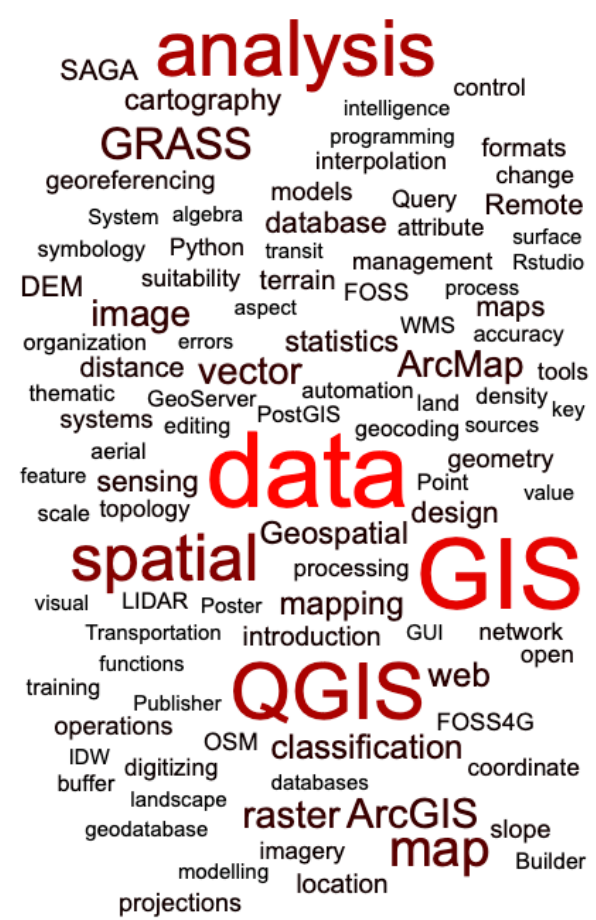

Figure 1. Keywords used to describe the geospatial educational resources

\section{REQUIREMENTS FOR THE CATALOGUE}

In this section, we review the requirements for an open catalogue for geospatial education resources. The requirements were established by qualitatively reviewing our needs as educators and how we would search for educational material using a catalogue. We found that in general the requirements align with the requirements for most generic catalogues. The most important requirements are the need for a metadata schema that describes the catalogue items appropriately and that the application should be open source as long-term funding is not available. The requirements of the catalogue are summarized below:

1. The application used for the catalogue:

1.1. Open source is preferred as long-term funding is not available.

1.2. Should be accessible on all platforms (i.e. Windows, Mac OS and Linux) and on various devices (e.g. personal computers and smartphones).

1.3. Should allow the administrator to specify a metadata schema profile and customize the schema (refer to Section $3)$.

1.4. The application can be self-hosted, or cloud based.

2. The user should be able to:

2.1. Add resource with descriptive metadata into the catalogue but would require administrator approval.

2.2. Request resource to be deleted (i.e. the administrator would review the reason and perform the action).

2.3. Update the metadata for a specific resource available in the catalogue.

2.4. List all resources under a specific theme based on the keywords.

2.5. Search resources based on various metadata elements.
3.2. Manage registered users.

3.3. Approve the metadata for a resource once the metadata is added by a user.

3.4. Delete the metadata for a resource if requested by a user.

\section{REVIEW OF EXISITING APPLICATIONS}

An extensive search for possible existing application that can be used for the catalogue was done. Numerous applications were identified during the initial search. However, on closer inspection only five application were selected to be reviewed again based on identified requirements. Strictly speaking, the majority of these applications are implementations for a repository (a place where things are deposited or stored) and not for implementing a catalogue (a list of descriptions of things). We evaluated the following applications:

- Islandora (https://islandora.ca)

Islandora is an open source repository that allows institutions to collaboratively manage, discover digital objects. Islandora is based on Drupal, Fedora and Solr.

- $\quad$ EPrints (https://www.eprints.org)

EPrints is a generic institutional repository building software that is intended to create highly configurable webbased repositories. EPrints is able to build repositories that can be configured to meet the particular requirements of a project.

- $\quad \operatorname{AtoM}$ (https://www.accesstomemory.org/en/)

AtoM is an open source archival description application. AtoM allows users to tag files and describe the objects using metadata standards built-in to the repository.

- Zenodo (https://zenodo.org)

Zenodo is an open access repository popular with researchers for achieving and preserving their datasets, software, reports and other digital artifacts. An attractive feature is that each submission is assigned a DOI.

- DSpace (http://dspace.org/introducing)

DSpace is an open source "out of the box" repository that allows institutions to preserve all types of digital content, including text, moving images, mpegs and datasets. The files or object and metadata is stored in a relational database and supports the use of PostgreSQL and ORACLE databases.

Although all of the evaluated applications had useful characteristics, two of the requirements were not fulfilled by any of these: the implementation of a new metadata profile or customizing an existing schema; and creating a metadata record without the need to upload a file. The evaluation revealed that implementing the catalogue using new web application technologies, such as Google Firebase and React, would be easier than adapting existing applications to suit our requirements.

\section{IMPLEMENTATION OF A CATALOGUE}

In this section, we describe an early implementation of the catalogue. The development of the catalogue is still in its initial stages, and further changes are planned.

3. The administrator should be able to:

3.1. Perform all functionality allowed by the user. 
For the backend of the catalogue, we decided to use Google Firebase $^{1}$. Firebase is a cloud-based NoSQL database that allows developers to quickly setup a backend for any web application. Additionally, Firebase provides other advantages, such as realtime database, a machine learning kit and performance monitoring. Each resource is stored in Firebase as a JSON objects with its various fields or attributes.

The front end or user interface of the catalogue was developed using JavaScript and specifically the React library. React is a very popular JavaScript library for creating user interfaces at the moment and allows the developer to break the interface up into components that can be updated without updating the entire page. Additionally, React also allows us to create responsive interfaces that automatically adjust to the resolution of device it is viewed on.

We have not yet worked on the usability and design of the interface of the catalogue, this would be in the final stages of the development process. Currently the landing page of the catalogue is a list of all the resources with an option to add a new resource or do a quick search based on the keywords. Refer to Figure 2. To list all the resources, the title, description, date, authors and keywords for all the resources are pulled from the Firebase database. The JSON objects returned is then used for the quick search using basic JavaScript functionalities. For the more advance search, the user would be able to search on all field using a Google like search or specifying specific fields. For example, retrieving all exercises (i.e. learning resource type) aimed at higher education (i.e. context).

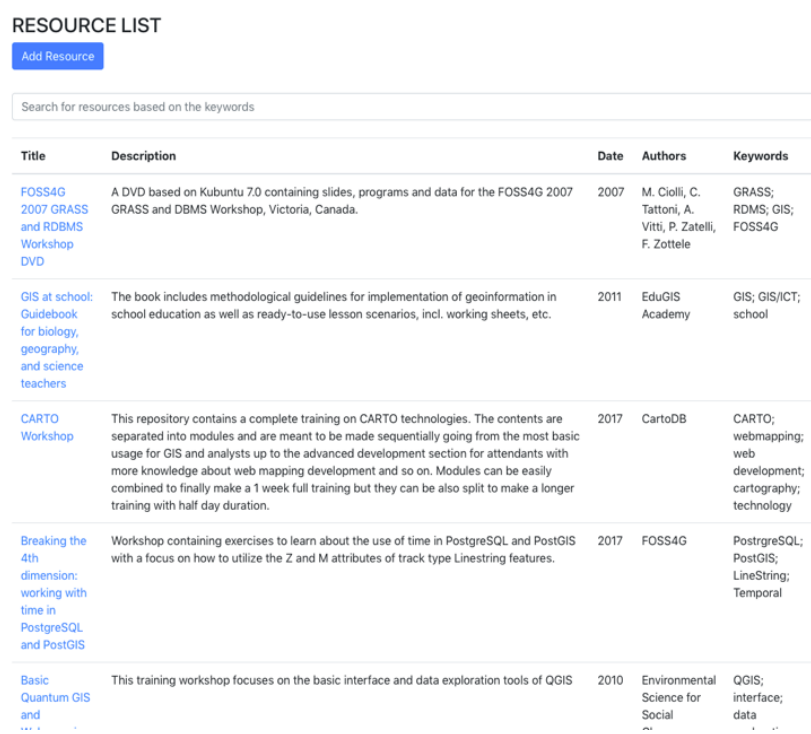

Figure 2. Current landing page of the catalogue displaying all the resource available

To add a new resource, the user would need to complete a form with various field linked to the metadata elements in Table 1. Where the list of options was predefined by the standard, the user can make use of the dropdown boxes to select the most appropriate option. Refer to Figure 3. However, some of the predefined options in the standard is not that self-explanatory and the user would need assistance to complete these. To address this, we are planning to add tooltips for the fields that provide the user with a short explanation of what information is required. Once the resource is added, it can be viewed, updated and deleted (see
Figure 4). At the moment, we have not yet implemented the user restrictions, but this is the next phase and will be implemented shortly.

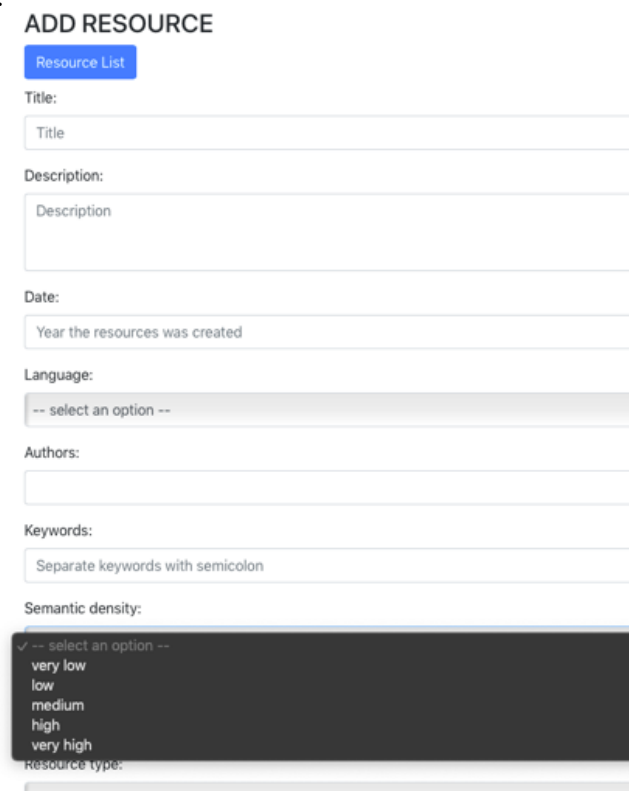

Figure 3. Part of the form that needs to be completed to add a new resource

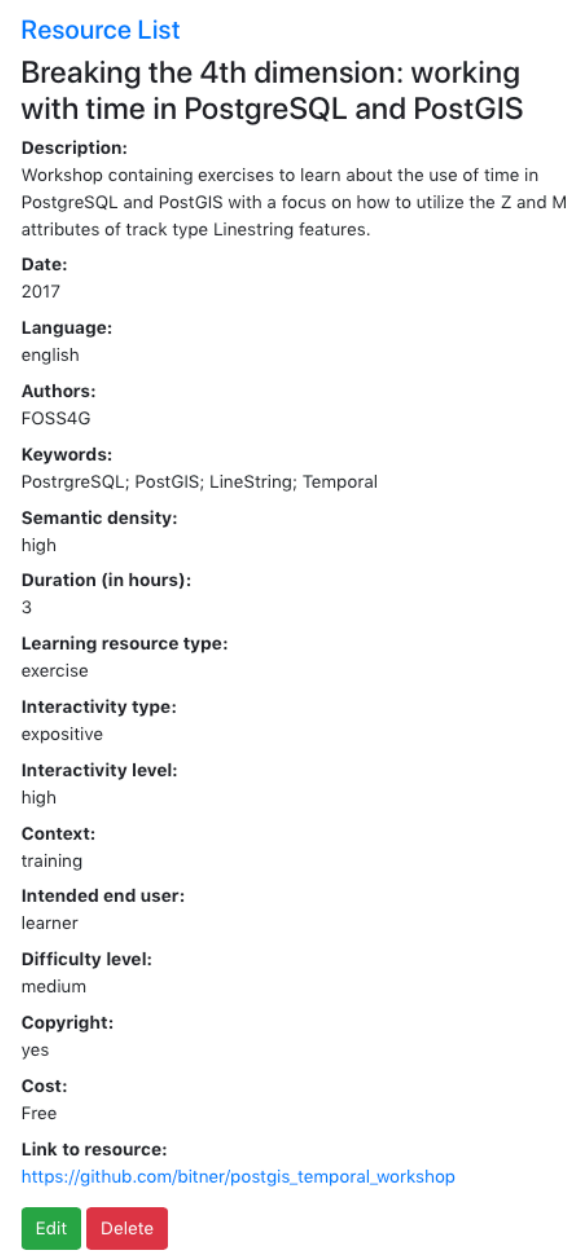

Figure 4. Viewing the metadata of a resource

\footnotetext{
${ }^{1}$ https://firebase.google.com
} 
Table 2 provides a summary of the requirements that are currently fulfilled by the custom catalogue implementation. The requirements not yet satisfied will be implemented within the next moth and thereafter undergo extensive testing.

Table 2. Overview of fulfilment of the requirements of the custom catalogue implementation

\begin{tabular}{|c|c|}
\hline Requirements & $\begin{array}{l}\text { Fulfill the } \\
\text { requirement }\end{array}$ \\
\hline $\begin{array}{l}\text { 1.1. Open source is preferred as long-term } \\
\text { funding is not available. }\end{array}$ & Yes \\
\hline $\begin{array}{l}\text { 1.2. Should be accessible on all platforms } \\
\text { and on various devices. }\end{array}$ & Yes \\
\hline $\begin{array}{l}\text { 1.3. Should allow the administrator to } \\
\text { specify a metadata schema profile and } \\
\text { customize the schema. }\end{array}$ & Yes \\
\hline $\begin{array}{l}\text { 1.4. The application can be self-hosted, or } \\
\text { cloud based. }\end{array}$ & Yes \\
\hline $\begin{array}{l}\text { 2.1. Add resource with descriptive metadata } \\
\text { into the catalogue but would require } \\
\text { administrator approval. }\end{array}$ & Yes \\
\hline $\begin{array}{l}\text { 2.2. Request resource to be deleted (i.e. the } \\
\text { administrator would review the reason } \\
\text { and perform the action). }\end{array}$ & Yes * \\
\hline $\begin{array}{l}\text { 2.3. Update the metadata for a specific } \\
\text { resource available in the catalogue. }\end{array}$ & Yes \\
\hline $\begin{array}{l}\text { 2.4. List all resources under a specific } \\
\text { theme based on the keywords. }\end{array}$ & Yes \\
\hline $\begin{array}{l}\text { 2.5. Search resources based on various } \\
\text { metadata elements. }\end{array}$ & Yes * \\
\hline $\begin{array}{l}\text { 3.1. Perform all functionality allowed by } \\
\text { the user. }\end{array}$ & Yes * \\
\hline 3.2. Manage registered users. & Yes * \\
\hline $\begin{array}{l}\text { 3.3. Approve the metadata for a resource } \\
\text { once the metadata is added by a user. }\end{array}$ & Yes * \\
\hline $\begin{array}{l}\text { 3.4. Delete the metadata for a resource if } \\
\text { requested by a user. }\end{array}$ & Yes * \\
\hline
\end{tabular}

* The implementation is in progress.

\section{DISCUSSION AND CONCLUSION}

In this paper, we reviewed the requirements for implementing a catalogue that can be used to index geospatial educational resources. As part of this review, we investigated many existing metadata schemas and tools that could possibly be used for the catalogue. Based on this review, we find that although the IEEE LOM schema is promising, it would be too complex to use as is; thus we believe a customized profile consisting of 20 selected elements would be more suitable for our purposes. Additionally, we identified the need for a custom catalogue, as existing open source tools are rather repositories and not catalogues. These repositories did not allow us to customize existing metadata schemas (generally Dublin Core were used in the repositories) and remove the requirement of uploading a file with every metadata record.

Additionally, this requirement of most repositories that the user has to upload the actual educational resource might have implications for the copyright or intellectual property rights (IPR). The terms and conditions of especially cloud-based services would need to be studied and clearly indicated to users before they submit any information. Thus, our focus was rather on developing a catalogue with the metadata that describes the educational resource with a link to the actual resource. In this case, there is no potential for conflict regarding copyright or IPR.
As part of the paper, we reviewed the 114 geospatial educational resources identified so far. From the sample of resources reviewed, there was a clear lack of resources for schools, and educators both at school and higher education level. The majority of the reviewed resources focus strongly on training a learner to perform a specific function in a software package, and not on general concepts or theory in the field. Through identifying these gaps in our initial analyses of available resources, we believe future efforts will be more informed. Thus such efforts might be most beneficial if they focus on developing educational resources specifically targeted at schools, helping educators with creating lesson plans, and teaching basic concepts in the field of geoinformation science and not focusing on specific software. While classifying the pedagogical information of the educational resources identified to date, we also recognized the need to extend some of the metadata elements used in our IEEE LOM profile. For example, the learning resource type does not include options for data stores, software packages or models, that would be useful resources for especially higher education students and educators.

The current implementation of the custom catalogue as presented in Section 6 does not yet consider the usability of the catalogue, but rather focus on implementing the functionalities identified through the requirements. After the implementation is complete, the catalogue will undergo extensive user testing to elicit feedback to further improve the usability and usefulness of the catalogue. For example, how would an average user search for a specific resource? Once we understand how people use the catalogue, we can improve the interface and interaction. We will also explore the use of machine learning to automatically classify and generate metadata about each new educational resource. The generated metadata can then be reviewed and revised by the user before submitting the information to the catalogue. We anticipate that this will then limit the amount of user input needed, and hopefully improve the quality of available information about each resource in the catalogue.

\section{ACKNOWLEDGEMENTS}

This research was supported by a 2018 Education and Capacity Building Initiatives from the ISPRS. We are grateful to Cameron Green and Azile Mdleleni for reviewing and classifying the educational resources.

\section{REFERENCES}

Hylén, J., 2006. Open Educational Resources: Opportunities and Challenges, Proceedings of Open Education, pp. 49-63.

IEEE 1484.12.1-2002, 2002. IEEE Standard for Learning Object Metadata, available online at

https://standards.ieee.org/standard/1484_12_1-2002.html

ISO 15836-1:2009, 2009. Information and documentation -The Dublin Core metadata element set -- Part 1: Core elements, International Organization for Standardisation (ISO), Geneva, Switzerland.

Littlejohn, A., 2003. Issues in Reusing Online Resources. In Reusing online resources: a sustainable approach to e-learning. Littlejohn (Ed.). Kogan Page: London. ISBN 0749439491.

Roy, D., Sarkar, S., Ghose, S., 2010. A Comparative Study of Learning Object Metadata, Learning Material Repositories, Metadata Annotation \& an Automatic Metadata Annotation Tool, Advances in Semantic Computing, 2, pp. 103-120. 